\title{
0968. The influence of hypothermia and catecholamines on guinea pig's small bowel motility in vitro
}

\author{
M Schörghuber ${ }^{1 *}$, E Tatzl $^{1}$, P Holzer ${ }^{2}$, W Toller ${ }^{1}$, S Fruhwald ${ }^{1}$ \\ From ESICM LIVES 2014 \\ Barcelona, Spain. 27 September - 1 October 2014
}

\begin{abstract}
Introduction
In critically ill patients early enteral nutrition (EN) preserves gastrointestinal (GI) integrity and motility and should be started as early as possible. We know that several therapeutic strategies, e.g. catecholamines or analgosedation, exert adverse effects on GI motility. ${ }^{1}$ What we do not know is whether therapeutic hypothermia has an influence on GI motility and thereby feeding intolerance.
\end{abstract}

\section{Objectives}

The aim of this study was to find out if guinea pig's small bowel motility is altered during hypothermia and after rewarming and if catecholamines cause alterations of peristalsis in this situation.

\section{Methods}

Guinea pig's small bowel segments of $8 \mathrm{~cm}$ length were set up in organ baths containing oxygenated Tyrode's solution. Peristalsis was elicited by luminal perfusion $(0.5 \mathrm{ml} / \mathrm{min})$ against an aboral resistance of 400 Pascal (Pa). Perfusion of the segments resulted in an increase of the intraluminal pressure up to a pressure threshold (PT; mean \pm SEM), where peristaltic contractions were triggered. The pressure was recorded at the aboral end of the segments. An increase of the PT indicates an inhibition of peristalsis, while a decrease of the PT represents a stimulation of peristalsis. A PT of $400 \mathrm{~Pa}$ was equated with a complete block of peristalsis. PT was firstly measured at $37^{\circ} \mathrm{C}$ temperature of the organ bath, after rapid cooling to $20^{\circ} \mathrm{C}$ and after rewarming to $37^{\circ} \mathrm{C}$ (control). In a second setting before rewarming one of the following substances were added to the organ baths: adrenaline $100 \mathrm{nM}$, dobutamine $100 \mu \mathrm{M}$, noradrenaline $1 \mu \mathrm{M}$. At $37^{\circ} \mathrm{C}$ PT was evaluated again.

\section{Results}

Basic PT was $49.6 \pm 6.5 \mathrm{~Pa}$. Lowering the bath temperature to $20^{\circ} \mathrm{C}$ led to a complete block of peristalsis in all tested segments $(\mathrm{PT}=400 \mathrm{~Pa}$, figure 1$)$. During rewarming all small bowel segments started peristaltic contractions spontaneously and showed normal peristalsis at $37^{\circ} \mathrm{C}$. In the second setting additional catecholamines resulted in a significantly delayed restart of peristalsis after rewarming and a persistent inhibition of peristalsis (i.e. higher PT) compared to control segments.

\section{Conclusions}

Our experimental setting demonstrates a distinct impairment of small bowel motility during hypothermia, a delayed restart and a persistent inhibition of motility in the presence of catecholamines, explaining the higher incidence of feeding intolerance in this group of patients.

\section{Authors' details}

'Medical University of Graz, Department of Anesthesiology and Intensive Care M, Graz, Austria. ${ }^{2}$ Medical University of Graz, Institute of Experimental and Clinical Pharmacology, Graz, Austria. 


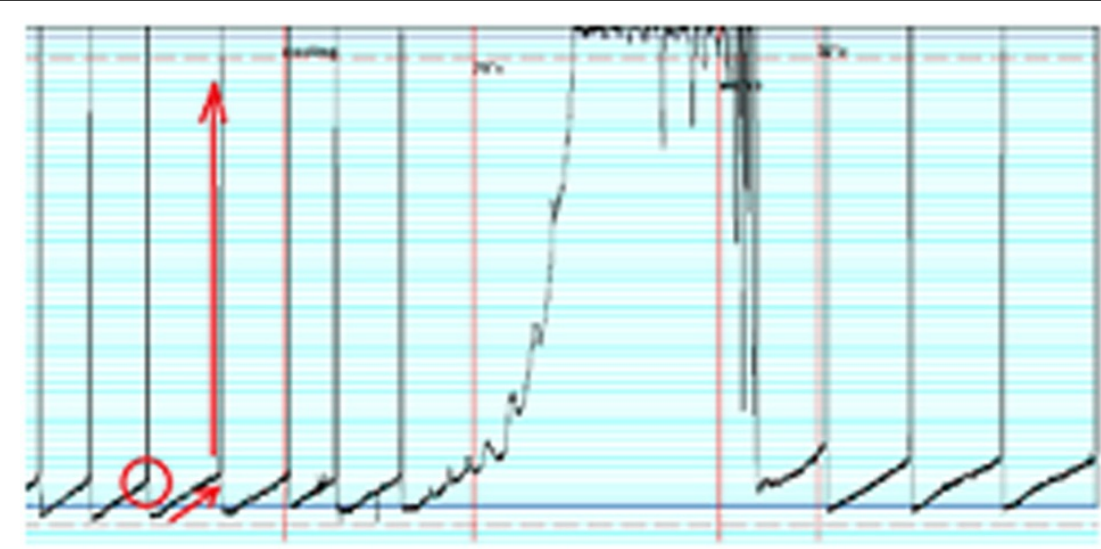

Figure 1 Alteration of peristalsis during hypothermia $\rightarrow$ incease of intraluminal pressure. O PT. $\uparrow$ peristaltic reflex

Table 1 PT and start of peristalsis after admission of catecho/amines compared to control. ${ }^{1}$ two-sided t-test. ${ }^{2}$ KruskalWallis.

\begin{tabular}{lllllll}
\hline & & \multicolumn{4}{c}{ Start of peristalsis after rewarming (\%) } \\
\hline & $\mathbf{P T}(\mathbf{P a})$ after rewarming & $\mathbf{p}^{\mathbf{1}}$ & Immediately & $<5$ minutes & $>5$ minutes & $\mathbf{P}^{\mathbf{2}}$ \\
\hline Control & $70.4 \pm 8.3$ & & 10 & 60 & 30 & $<0.001$ \\
\hline Adrenaline & $182.7 \pm 39.3$ & 0.019 & 0 & 55 & 45 & $<0.001$ \\
\hline Dobutamine & $264.2 \pm 46.6$ & 0.001 & 0.008 & 40 & 55 & $<0.001$ \\
\hline Noradrenaline & $223.9 \pm 48.4$ & 0.01 & & & \\
\hline
\end{tabular}

Published: 26 September 2014

\section{Reference}

1. Fruhwald S, Holzer P, Metzler H: Intestinal motility disturbances in intensive care patients: pathogenesis and clinical impact. Intensive Care Medicine 2007, 33:36-44.

doi:10.1186/2197-425X-2-S1-P67

Cite this article as: Schörghuber et al:: 0968. The influence of hypothermia and catecholamines on guinea pig's small bowel motility

in vitro. Intensive Care Medicine Experimental 2014 2(Suppl 1):P67.

\section{Submit your manuscript to a SpringerOpen ${ }^{\mathcal{D}}$ journal and benefit from:}

- Convenient online submission

- Rigorous peer review

- Immediate publication on acceptance

- Open access: articles freely available online

- High visibility within the field

- Retaining the copyright to your article 